\title{
The Coupled Aerosol and Tracer Transport model to the Brazilian developments on the Regional Atmospheric Modeling System (CATT-BRAMS) - Part 2: Model sensitivity to the biomass burning inventories
}

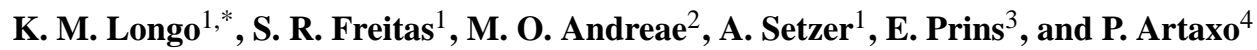 \\ ${ }^{1}$ Center for Weather Forecasting and Climate Studies, INPE, Cachoeira Paulista, Brazil \\ ${ }^{2}$ Max Planck Institute for Chemistry, Mainz, Germany \\ ${ }^{3}$ UW-Madison Cooperative Institute for Meteorological Satellite Studies, Madison, WI, USA \\ ${ }^{4}$ Institute of Physics, University of São Paulo, Brazil \\ * now at: Earth System Science Center, INPE, São José dos Campos, Brazil
}

Received: 20 April 2007 - Published in Atmos. Chem. Phys. Discuss.: 20 June 2007

Revised: 19 March 2010 - Accepted: 10 June 2010 - Published: 1 July 2010

\begin{abstract}
We describe an estimation technique for biomass burning emissions in South America based on a combination of remote-sensing fire products and field observations, the Brazilian Biomass Burning Emission Model (3BEM). For each fire pixel detected by remote sensing, the mass of the emitted tracer is calculated based on field observations of fire properties related to the type of vegetation burning. The burnt area is estimated from the instantaneous fire size retrieved by remote sensing, when available, or from statistical properties of the burn scars. The sources are then spatially and temporally distributed and assimilated daily by the Coupled Aerosol and Tracer Transport model to the Brazilian developments on the Regional Atmospheric Modeling System (CATT-BRAMS) in order to perform the prognosis of related tracer concentrations. Three other biomass burning inventories, including GFEDv2 and EDGAR, are simultaneously used to compare the emission strength in terms of the resultant tracer distribution. We also assess the effect of using the daily time resolution of fire emissions by including runs with monthly-averaged emissions. We evaluate the performance of the model using the different emission estimation techniques by comparing the model results with direct measurements of carbon monoxide both near-surface and airborne, as well as remote sensing derived products. The model results
\end{abstract}

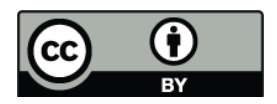

Correspondence to: K. M. Longo (karla.longo@inpe.br) obtained using the 3BEM methodology of estimation introduced in this paper show relatively good agreement with the direct measurements and MOPITT data product, suggesting the reliability of the model at local to regional scales.

\section{Introduction}

The high concentrations of aerosol particles and trace gases observed in the Amazonian and Central Brazilian atmosphere during the dry season are with the result of intense anthropogenic biomass burning activity (vegetation fires). A widely cited estimate suggests that biomass burning in South America is responsible for the emission of $30 \mathrm{Tg}_{\mathrm{gear}}{ }^{-1}$ of aerosol particles to the atmosphere (Andreae, 1991). Most of the particles are in the fine particle fraction of the size distribution, which can remain in the atmosphere for approximately a week (Kaufman, 1995). In addition to aerosol particles, biomass burning produces water vapor and carbon dioxide, and is a major source of other compounds such as carbon monoxide $(\mathrm{CO})$, volatile organic compounds, nitrogen oxides, and organic halogen compounds (Andreae and Merlet, 2001). In the presence of abundant solar radiation and high concentrations of $\mathrm{NO}_{\mathrm{x}}$, the oxidation of $\mathrm{CO}$ and hydrocarbons results in ozone $\left(\mathrm{O}_{3}\right)$ formation. In this way, biomass burning emissions have a strong impact on tropospheric and stratospheric chemical composition, and are an

Published by Copernicus Publications on behalf of the European Geosciences Union. 
important agent of weather and climate change. Therefore, the estimation of the amounts injected into the atmosphere at regional as well as global scales is needed.

The most common way to estimate emissions from vegetation fires, the so-called "bottom-up" approach, is through an initial estimation of the quantity of biomass consumed through combustion. This estimation can be accomplished if information on the aboveground biomass density, the combustion factor (the fraction of the fuel load actually combusted) and the area burned is available. Following this method, the amount of specific chemical species can be obtained by using the associated emission factor (fraction of mass of compound emitted per mass of fuel burned, on a dry mass basis). A thorough review of emission factors was presented by Andreae and Merlet (2001).

Several authors have presented estimates of biomass consumption by combustion. Hao and Liu (1994) built a database for the spatial (5 degrees) and temporal (monthly) distribution of the amount of biomass burned in tropical America, Africa, and Asia during the late 1970s. Schultz (2002) and Generoso et al. (2003) proposed the use of fire-count data from the Along Track Scanning Radiometer (ATSR) to estimate the typical seasonal and interannual variability of biomass burning emissions. Duncan et al. (2003) combined the same ATSR fire-count data and the Advanced Very High Resolution Radiometer (AVHRR) World Fire Atlas, and using the total Ozone Mapping Spectrometer (TOMS) Aerosol Index as a proxy to estimate the strength of emissions, the authors estimated the mean variability of $\mathrm{CO}$ emissions from biomass burning. The Global Wildland Fire Emission Model (GWEM) (Hoelzemann et al., 2004) provides emissions for several species based on the data from the European Space Agency's monthly Global Burnt Scar satellite product (GLOBSCAR), and more recently GBA2000 of the Joint Research Centre of the European Commission (JRC) and results from the Lund-PotsdamJena Dynamic Global Vegetation Model (LPJ-DGVM) for the year 2000. Giglio et al. (2006) and van der Werf et al. (2006), using burned-area estimates from remote sensing, a biogeochemical model, and emission factors from the literature, estimated fire emissions during the 8-year period from 1997 to 2004. This dataset, called Global Fire Emissions Database (GFEDv2), has $1^{\circ} \times 1^{\circ}$ spatial resolution with 8 -day and one-month time steps. GWEM yields over 5 times less CO emissions than GFED for South America, and predicts an early emission maximum in August, in contrast to the agreement on a maximum in September by all the other inventories cited above. The relatively poor result of GWEM for South America was attributed mainly to the insufficient performance of the global burnt area products GLOBSCAR (Hoelzemann et al., 2004) and GBA2000 (Hoelzemann et al., 2007) over this region. The most recent GWEM version (1.4), which includes a correction for South America based on the method presented here, yields estimated $\mathrm{CO}$ emissions increased by $30 \%$ and an improved seasonality, shifting the emission maximum to September (Hoelzemann et al., 2007). Alternative methodologies use the fire radiative energy to estimate the emission rates (Kaufman et al., 2003; Riggan et al., 2004; Ichoku and Kaufman, 2005; Wooster et al., 2005; Freeborn et al., 2008; Pereira et al., 2009).

In this paper we describe and evaluate an estimation technique for biomass burning emissions based on a combination of remote sensing fire products and field observations. The resulting inventory is then applied to simulate the 2002 dry season pyrogenic CO over South America (SA), when and where the field campaigns LBA Smoke, Aerosols, Clouds, Rainfall, and Climate (SMOCC) and Radiation, Cloud, and Climate Interactions in the Amazon during the dry-to-wet Transition Season (RaCCI) took place. The paper is organized as follows: in Sect. 2, the technique is described. In Sect. 3, we evaluate the model results for CO, using surface measurements, airborne and remote-sensing-retrieved data. Our conclusions are discussed in Sect. 4.

\section{The biomass burning emissions inventory}

The biomass burning emission parameterization method used in this paper, which we named Brazilian Biomass Burning Emission Model (3BEM), is based on the approach of Freitas et al. (2005). Basically, for each fire pixel detected, the mass of the emitted tracer is calculated by the following expression, which takes into consideration the estimated values for the amount of above-ground biomass available for burning $(\alpha)$, the combustion factor $(\beta)$, the emission factor $(\mathrm{EF})$ for a certain species $[\eta]$ from the appropriate type of vegetation, and the burning area $\left(a_{\text {fire }}\right)$ for each burning event.

$M^{[\eta]}=\alpha_{\mathrm{veg}} \cdot \beta_{\mathrm{veg}} \cdot \mathrm{EF}_{\mathrm{veg}}^{[\eta]} \cdot a_{\mathrm{fire}}$,

A hybrid remote-sensing fire product is used to minimize missing remote sensing observations. The fire database actually utilized is a combination of the Geostationary Operational Environmental Satellite - Wildfire Automated Biomass Burning Algorithm (GOES WF_ABBA product (cimss.ssec. wisc.edu/goes/burn/wfabba.html; Prins et al., 1998), the Brazilian National Institute for Space Research (INPE) fire product, which is based on the Advanced Very High Resolution Radiometer (AVHRR) aboard the NOAA polar orbiting satellites series (www.cptec.inpe.br/queimadas; Setzer and Pereira, 1987), and the Moderate Resolution Imaging Spectroradiometer (MODIS) fire product (modis-fire.umd.edu; Giglio et al., 2003). The three fire product databases are combined using a filter algorithm to avoid double counting of the same fire, by eliminating additional fires within a circle of $1 \mathrm{~km}$ radius. The fire detection maps are merged with 1-km resolution land use data (Belward, 1996; Sestini et al., 2003) to provide the associated emission (EF) and combustion $(\beta)$ factors through a look-up-table. The corresponding carbon density $(\alpha)$ is defined from the carbon in live vegetation data, estimated using Olson et al. (2000) 


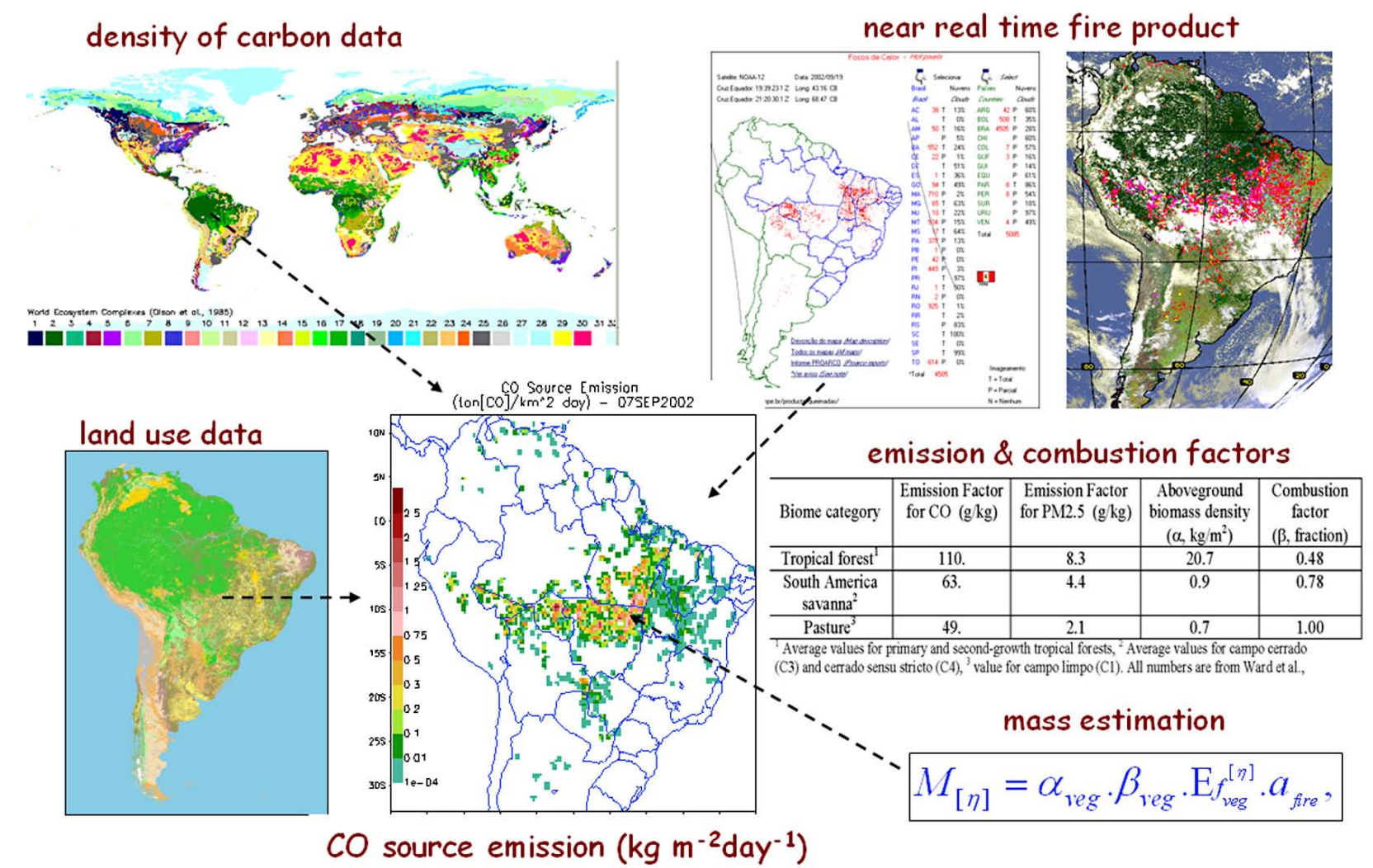

Fig. 1. Cartoon describing all sources of information used to estimate biomass burning emissions according to the 3BEM methodology.

and Houghton et al. (2001). The land use map for the Amazon basin was updated with data provided by the PROVEG project (Sestini et al., 2003), and is based on the year 2000. One shortcoming of the 3BEM methodology is the use of static land cover and carbon content data sets. Therefore, on pixels where fires took place previously or where the land use changed, there may be a mismatch between the actual values and those prescribed by the data sets. The emission and combustion factors for each biome are based on the work of Ward et al. (1992) and Andreae and Merlet (2001). The burnt area is estimated from the instantaneous fire size retrieved by remote sensing, when available, or by statistical properties of the fire scars. Fires detected according to the GOES WF_ABBA product have the burnt area estimated by the instantaneous fire size for each non-saturated and noncloudy fire pixel, where it is possible to retrieve sub-pixel fire characteristics. For GOES WF_ABBA detected fires that have no information about the instantaneous fire size, a mean instantaneous fire size of $0.14 \mathrm{~km}^{2}$ (calculated from the GOES ABBA database of the previous years) is used. For fires detected by the MODIS and AVHRR systems, a mean value of $0.22 \mathrm{~km}^{2}$ of burnt area is applied according to J. M. Pereira (personal communication, 2007). The total emission per species for each model grid box, taking into account all the possible observed sub-grid fires burning different types of vegetation, is then given by:

$$
Q^{[\eta]}(t)=\frac{r(t)}{\rho_{0} \Delta V} \sum_{\substack{\text { fires_E } \\ \text { Grid_Box }}} M^{[\eta]},
$$

where $\rho_{0}$ is the basic state air density and $\Delta V$ is the volume of the grid cell. The Gaussian function $r(t)$, centered at the time of the maximum fire activity (17:45 UTC), modulates the emission diurnal cycle (Prins et al., 1996). Then, the emission sources are distributed with the same spatial and temporal resolution as that of the atmospheric transport model, and assimilated daily according to the biomass burning spots actually observed by the satellites. Figure 1 summarizes all the sources of information used to estimate biomass burning emissions by the 3BEM technique. In addition to the biomass burning emissions, we included the biofuel use and agricultural waste burning inventory developed by Yevich and Logan (2003).

In this study, three other biomass burning emission inventories, built with different approaches and space-time resolution are also considered. The first one is the EDGAR database climatology (Olivier et al., 1996, 1999) which has monthly variation and $2.5^{\circ}$ resolution. We also use the climatology of Duncan et al. (2003, hereafter D2003) and Lobert et al. (1999) with monthly variation and $1^{\circ}$ resolution. Finally, GFEDv2 with 8-day time resolution and $1^{\circ}$ spatial distribution for 2002 is also included. These three inventories are 

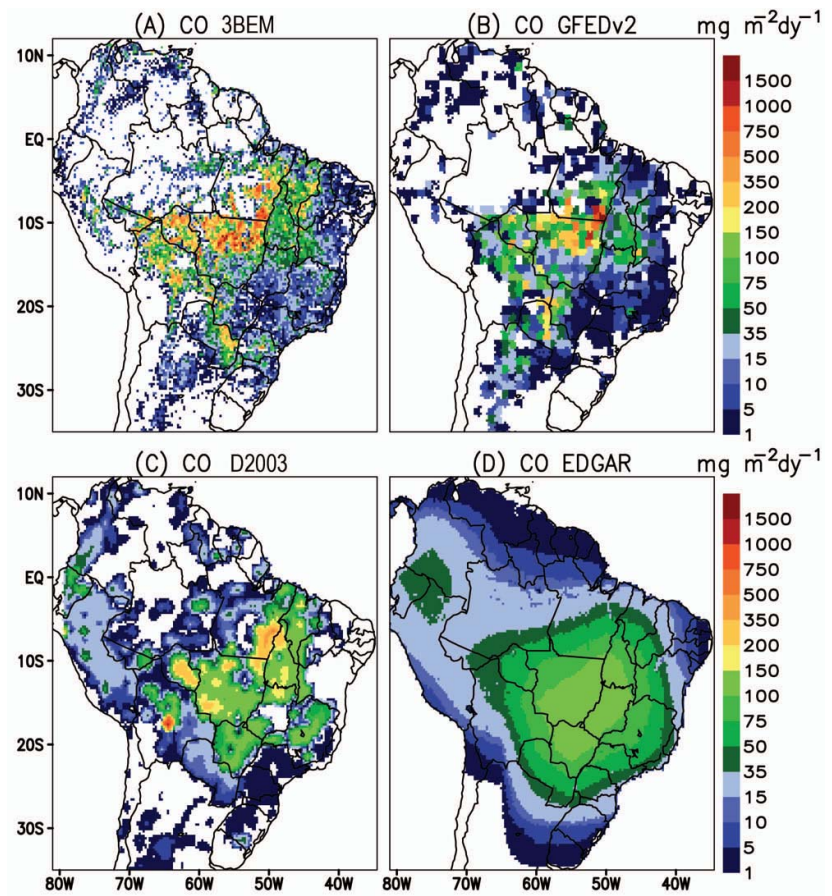

Fig. 2. The four biomass burning inventories showing the spatial distribution of the $\mathrm{CO}$ emission estimation obtained as 3 monthly mean (AUG-SEP-OCT) 2002 and in units $\mathrm{mg} \mathrm{m}^{-2} \mathrm{~d}^{-1}$ : (A) with the technique described in this paper (3BEM), (B) GFEDv2, (C) D2003 and (D) EDGAR.

shown together with 3BEM in Fig. 2 and Fig. 3. In Fig. 2 we show the spatial biomass-burning $\mathrm{CO}$ emission estimation $\left(\mathrm{mg} \mathrm{m}^{-2} \mathrm{dy}^{-1}\right.$ ) as a 3-month average (August-SeptemberOctober) and at $35-\mathrm{km}$ horizontal space resolution. Panel (a) shows the estimation obtained by 3BEM, on panel (b) is GFEDv2, (c) shows D2003, and (d) EDGAR. The estimates from 3BEM, GFEDv2 and D2003 show general agreement in terms of emissions being located mainly in the so-called "Arc of deforestation" (AD, the area around latitude $10^{\circ} \mathrm{S}$ between longitude $67^{\circ} \mathrm{W}$ to $50^{\circ} \mathrm{W}$ and from latitude $10^{\circ} \mathrm{S}$ to $5^{\circ} \mathrm{S}$ around longitude $50^{\circ} \mathrm{W}$ ), located on the border between the Amazon forest and the main area of intense land use and land cover change for cropland and pasture. They also have strong gradients of the emission field. On the other hand, EDGAR prescribes a too wide and smooth emission field with values less than $150 \mathrm{mg} \mathrm{m}^{-2} \mathrm{day}^{-1}$. On areas located in Brazil to the south of the $\mathrm{AD}$ (areas dominated by savanna, croplands and pastures), D2003 emissions are several times higher than 3BEM and GFEDv2. In general, GFEDv2 and 3BEM have similar estimation on the east side of the AD, but strong disagreement on the west side, mainly over Rondonia State where the LBA-SMOCC/RaCCI field campaign took place. Figure 3 introduces the time series for the total pyrogenic $\mathrm{CO}$ emission estimate from $\mathrm{SA}$ (in $\mathrm{Tg}$ ) on a daily basis. Note that, as they are based on fire count detection,

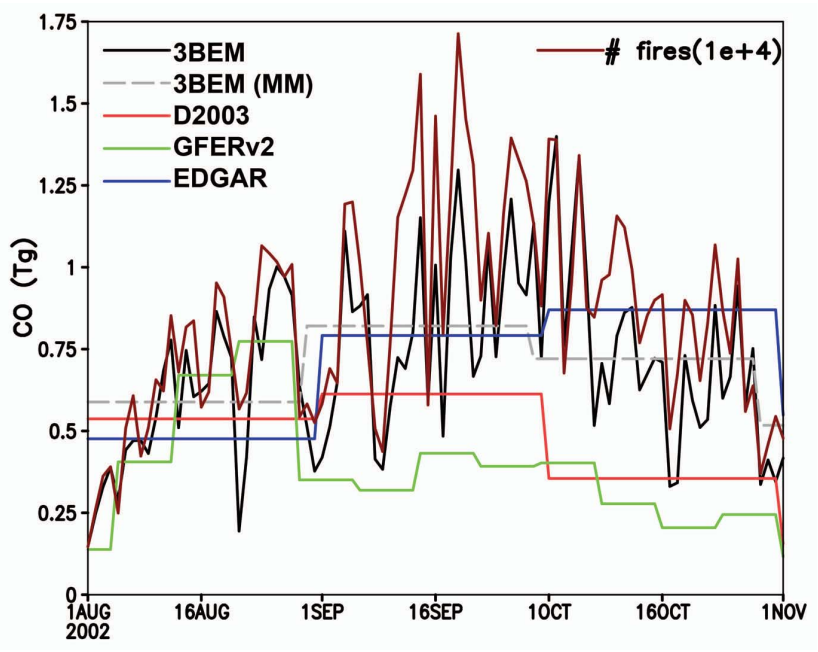

Fig. 3. The four biomass burning inventories: time series for the total pyrogenic $\mathrm{CO}$ emission estimate from SA (Tg) from 1 August to 1 November 2002 with 3BEM (daily variation, black), EDGAR (monthly variation, blue), D2003 (monthly variation, red), and GFEDv2 (8-day time variation, green). Also the monthly mean of 3BEM (grey) and the number of fire counts are shown.

3BEM emissions are very well correlated with the number of fires detected within South America, but they are not directly proportional due to the different biomes and associated emission factors attributed to each fire location. GFEDv2 and 3BEM are comparable during August, but GFEDv2 becomes much lower in September, a behavior not expected since this month corresponds to the peak of the burning season. In October, fires started to be inhibited by rainfall and presented a sharp reduction in number during the last week. In this case, 3BEM, GFEDv2 and D2003 showed the expected decrease, while EDGAR predicted a small increase for October. The monthly mean of 3BEM estimation is also shown, as it will be used later to elucidate the role of the diurnal variation of 3BEM for model performance.

The preceding discussions and comparisons highlight the additional features of 3BEM relative to the other three inventories: a spatial resolution that can be as fine as the pixel size of the satellite sensor used for the fire detection, a temporal resolution of one day or less, and also the fact that the emissions are placed only in regions where fires were in fact observed. We shall next explore the sensitivity of the atmospheric transport model to the inclusion of this level of detail in the inventory.

\section{Model CO results and evaluation using 2002 dry season data}

The five inventories described above were introduced into the CATT-BRAMS model system (Freitas et al., 2009). Simulations for the 2002 dry season were performed to compare 
model results using the inventories described with directly observed and remote-sensing-derived data.

The model configuration had 2 grids: the coarse grid with 140-km horizontal resolution covering the South American and African continents, its main purpose being to simulate the intermittent smoke inflow from the African fires to South America and to coordinate with and compare to the longrange transport of smoke from fires in South America to the Atlantic Ocean; and the nested finer grid with a horizontal resolution of $35 \mathrm{~km}$, covering only SA. The vertical resolution for both grids varies telescopically with higher resolution at the surface $(150 \mathrm{~m})$, increasing stepwise with a ratio of 1.07 up to a maximum vertical resolution of $850 \mathrm{~m}$ at the top of the model at $23 \mathrm{~km}$ (a total of 42 vertical levels). The simulation started at 00:00 UTC on 15 July 2002 and the results for August, September and October are discussed. More details about the model configuration can be found in Freitas et al. (2009). Five tracers were simulated, representing CO emitted according to each inventory with the same initial values.

The loss of $\mathrm{CO}$ by chemical transformation is included through a linearized removal with a lifetime of 30 days (Seinfeld and Pandis, 1998). Since the lifetime of CO is long, from 50 to occasionally a minimum of 15 days (Mauzerall et al., 1998), CO acts essentially as a passive tracer in the simulation. The $\mathrm{CO}$ in the simulations tends to flow out of the model, especially above the boundary layer, and boundary conditions control the concentration more than the linearized chemical removal (see Freitas et al., 2009 for more details). In this case, the simulation was carried out with five $\mathrm{CO}$ tracers according to the following specifications. The tracers named COE, COD, COGFED, CO3BEM and CO3BEM_M did not include the plume rise mechanism, with the total $\mathrm{CO}$ mass released into the model layer closest to the surface. The source emission inventories used for the three first tracers were EDGAR, D2003 and GFEDv2, respectively. The inventory for CO3BEM and CO3BEM_M was 3BEM, but for the last tracer, 3BEM was monthly averaged in order to analyze the effect of the daily temporal resolution; this inventory is referred as $3 \mathrm{BEM}(\mathrm{MM})$. As stated before, in this simulation, the plume rise process was not included, in order to provide a consistent comparison of 3BEM with the others inventories (see Freitas et al. (2006) for an evaluation of the inclusion of the plume rise mechanism).

In the following sub-sections we will compare these model results with observations at three different scales: local near-surface-level measurements; regional - airborne vertical profiles; and large scale - remote sensing data.

\subsection{Model comparison with SMOCC/RaCCI 2002 surface measurements}

In the framework of the SMOCC/RaCCI campaign, from 10 September to early November 2002, measurements of CO near surface level were performed at the Fazenda Nossa Sen- hora Apareçida (FNS) pasture site $\left(10.75^{\circ} \mathrm{S}, 62.37^{\circ} \mathrm{W}\right)$, near Ouro Preto do Oeste in Rondônia, Brazil (Trebs et al., 2004). The number of fires detected and consequentially the atmospheric smoke loading in Amazonia typically show substantial interannual variability, with a clear positive trend between 2000 and 2005 (Koren et al., 2007; Schroeder et al., 2009; Koren et al., 2009). According to Koren et al. (2007), the number of fires doubled and the smoke loading increased by $60 \%$ during this period. The fire activities underwent a strong decrease in 2006, to recover again in 2007 (Schroeder et al., 2009). Actually, the fire incidence in Amazonia is directly associated with deforestation activities (not shown). Therefore, 2002 can be considered a typical year concerning fire activities in Amazonia, and the measurements and simulations presented here should be very representative of the climatological pattern.

Figure 4a shows the $\mathrm{CO}$ time series, comparing observations and the model results obtained with the five different emission estimates: 3BEM (and MM), EDGAR, GFEDv2 and D2003. This comparison between the near-surface daily average measurements and model results clearly indicates a better skill of the 3BEM inventory relatively to the others. The model CO using the 3BEM (CO3BEM) presents a time variability and range of values much more consistent with the near-surface measurements. While we notice that the CO3BEM does not follow very closely the observations during periods when the atmosphere is very polluted, such as the period from 19 to 22 September, this underestimation might be related to failure to detect fires below the thick smoke column. In contrast, when using inventories with monthly time resolution like EDGAR and D2003, the model could not capture the observed time variability of the near-surface $\mathrm{CO}$ concentration. Note also that GFEDv2 with 8-day time resolution was not able to reproduce the time variability of the concentration values, either. Using the monthly-mean version of 3BEM (CO3BEM_M) deteriorates the CO3BEM results, not only in terms of the simulated time variability but also of the absolute value of concentration, increasing the mismatch between the simulated and observed CO.

This discussion is also supported by the linear regression of observed $\mathrm{CO}$ versus modeled values (Fig. 4b) with correlation coefficients $\left(R^{2}\right)$ of approximately $0.69,0.37,0.33$, 0.03 and 0.33 for 3BEM, D2003, GFEDv2, EDGAR and 3BEM(MM), respectively. The large standard deviation of the mean of the observed $\mathrm{CO}$ and the strong day-to-day variability are due the proximity of the measurement site to many fire spots. While the emission inventories based on climatologic information are not able to capture this variability and the intensity of the emissions, the 3BEM methodology closely follows the observations, both in terms of intensity and day-to-day variability. Relying on monthly means of 3BEM, the correlation coefficient drops from 0.69 to 0.33 .

As the five tracers were simulated using the same dynamics, the results of this section point out the requirement for accurate information regarding timing and location of fires 

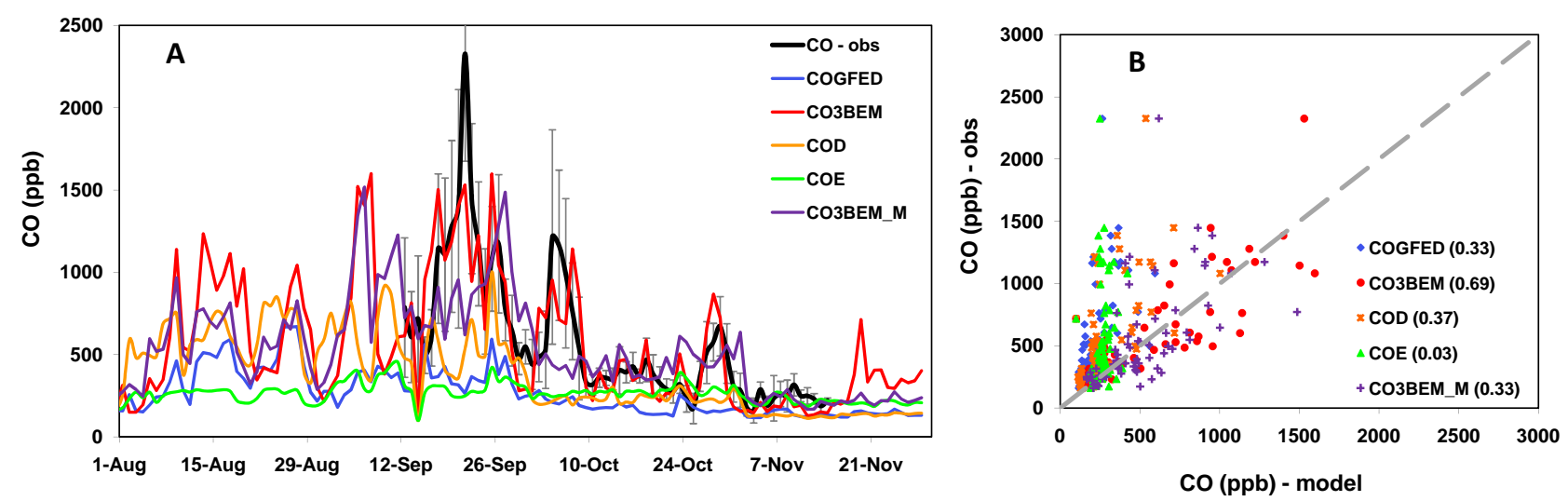

Fig. 4. Time series and scatter plot with linear regression with comparison between near surface CO (ppb), observed (black) and model results with the 3BEM (CO3BEM, red) emission inventory, 3BEM monthly mean (CO3BEM_M, purple), EDGAR (green), D2003 (orange) and GFEDv2 (blue). The measurements were daily-averaged and centered at 1200UT. The error bars are the standard deviations of the mean values. The model results are presented as instantaneous values at 12:00 UTC.

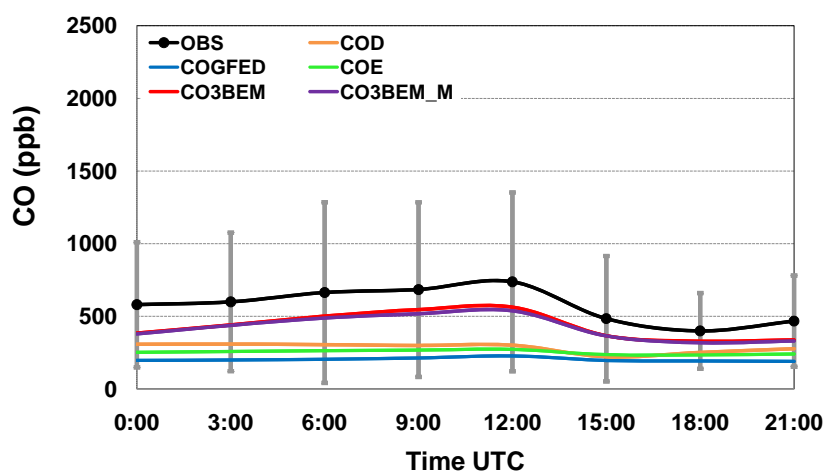

Fig. 5. Diurnal cycle of near surface CO mixing ratio (ppb), as time average, observed during the entire SMOCC field campaign (black color). Model results with the 3BEM emission inventory (CO3BEM, red), 3BEM monthly mean (CO3BEM_M, purple), EDGAR (green), D2003 (orange) and GFEDv2 (blue) are also shown.

in the emissions inventories in order to simulate realistically the time variability of near-surface air pollution.

The diurnal cycle of the observed $\mathrm{CO}$ mixing ratio and of the simulated $\mathrm{CO}$ tracers is discussed in the following. Figures 5 and 6 show the mean diurnal cycle of surface $\mathrm{CO}$ (ppb) for the entire field campaign and for the more intensely polluted period (12 September to 10 October), respectively. For the observations, the standard deviation (STD) of the CO is shown as well. It is evident from these two figures that the maximum mean value of the observed $\mathrm{CO}$ occurs around 12:00 UTC (08:00 local time), an effect associated with continuing nocturnal emissions (probably mostly from the smoldering phase) into a stable, shallow nocturnal boundary layer that retains the smoke close to the surface. After sunrise, the vertical deepening of the convective boundary layer di-

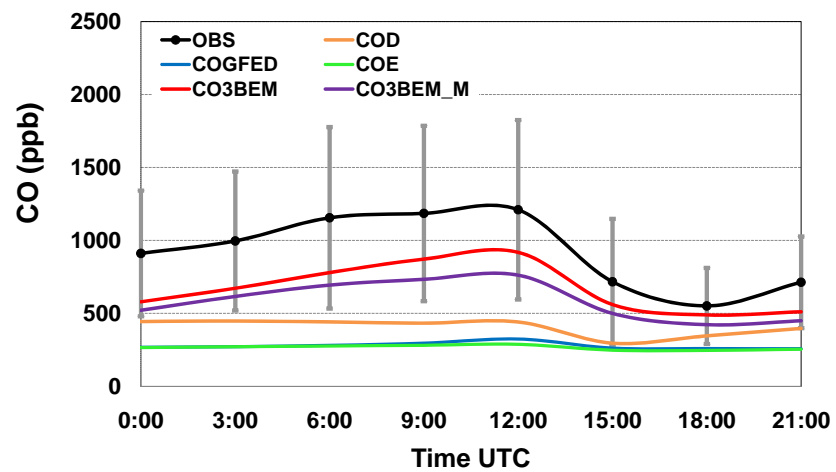

Fig. 6. Diurnal cycle of near surface $\mathrm{CO}$ mixing ratio (ppb), as time average, observed during the intense polluted time period (12 September to 10 October) of the SMOCC field campaign (black color). Model results with the 3BEM emission inventory (CO3BEM, red), 3BEM monthly mean (CO3BEM_M, purple), EDGAR (green), D2003 (orange) and GFEDv2 (blue) are also shown.

lutes the near-surface $\mathrm{CO}$ and mixing ratios decrease in spite of growing emissions, which have their maximum intensity around 18:00 UTC. After this time, the $\mathrm{CO}$ mixing ratio begins to increase due to the still high emission rates and because at this time the mixed layer depth has already reached its maximum value. The maximum values for the mean diurnal cycles in the two periods are approximately $730 \mathrm{ppb}$ and $1200 \mathrm{ppb}$ at 12:00 UTC, and the minimum values $400 \mathrm{ppb}$ and $580 \mathrm{ppb}$ at 18:00 UTC, respectively.

In the model results, all tracers follow the typical temporal evolution of the observations, peaking around 12:00 UTC and decreasing during the afternoon, thus indicating that the planetary boundary layer evolution dictates the diurnal cycle of the near-surface smoke concentration. Figure 5 

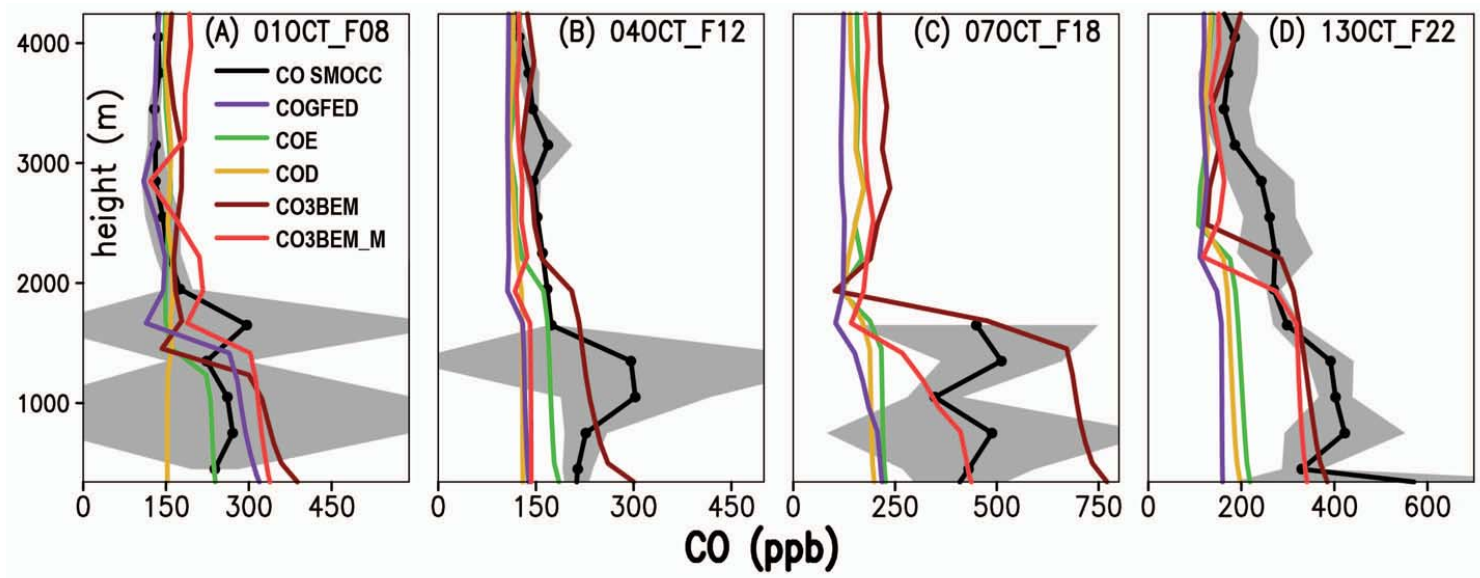

Fig. 7. Comparison between $\mathrm{CO}$ mixing ratio (ppb) observed during four flights of the SMOCC/RaCCI field campaign (black solid line represents the mean while the grey zone shows the standard deviation range) and model results: using the EDGAR inventory (green), D2003 (orange), 3BEM (CO3BEM, dark red), 3BEM monthly mean (CO3BEM_M, red) and GFEDv2 (purple).

demonstrates that, considering the mean over the entire period, all inventories underestimate the near-surface CO. However, they are all inside the STD of the observations. Note that EDGAR, D2003 and GFEDv2 have similar behavior while the 3BEM-based emissions yield the best model results in comparison to the observations. Considering only the time period of extreme pollution, the underestimation still exists, but CO3BEM and CO3BEM_M, based on 3BEM, compare much better to observations, with values being inside the STD range most of the time. COD shows larger underestimation, but is within the STD at the end of the afternoon. COE and COGFED present the worst comparison. Note also that using the monthly mean of 3BEM degrades the model results, indicating that including the actual time of the fire occurrence is particularly relevant in extreme conditions.

\subsection{Model comparison with SMOCC/RaCCI 2002 airborne measurements}

In order to evaluate the models' skill in describing the vertical structure of the smoke haze layer and to examine their sensitivity to the choice of emission fields, we performed a comparison of the simulated CO profiles in the PBL and lower troposphere with observed data using SMOCC/RaCCI campaign airborne measurements (Andreae et al., 2004). The typical maximum altitude reached by the aircraft was $5 \mathrm{~km}$. Figure 7 shows the vertical profiles of model results and observations for four flights, from 01 to 13 October (from the 16 flights we selected 4 relevant for this discussion). The mean and STD of the observed CO profiles are shown; note that STD represents the actual variability of the concentrations in the vertical layer, not the measurement error. For the first analyzed flight (Fig. 7a), all simulated tracers show reasonable comparison with the $\mathrm{CO}$ observations. The other results (Fig. 7b-d) depict the common situation of EDGAR, GFEDv2 and D2003 model predictions, which present a PBL typically much cleaner than observations, with the model results for $\mathrm{CO}$ mixing ratio ranging from 150 to $300 \mathrm{ppb}$. D2003 and GFEDv2 give the worst performance, in spite of their better horizontal resolution and estimation approach when compared to EDGAR. In contrast, the 3BEM (CO3BEM) and 3BEM(MM) (CO3BEM_M) model results present more variability on a day-to-day basis, with values ranging from 150 to $750 \mathrm{ppb}$, following more closely the observed pattern. Typically, the large STDs are due to aircraft passages through isolated smoke plumes, and even for those cases the 3BEM model results usually better represent the mean values. As expected, the model resolution of $35 \mathrm{~km}$ did not allow the point-by-point reproduction of the effect of sub-grid phenomena in the profiling data.

The overall performance of the five emission estimates can be evaluated in Fig. 8, where the mean $\mathrm{CO}$ observed profile and its STD for the sixteen SMOCC flights are presented together with the mean $\mathrm{CO}$ model profiles from the five emission estimates. The CO from 3BEM follows very closely the mean observed $\mathrm{CO}$ profile. However, using 3BEM with monthly mean emissions (CO3BEM $\triangle$ M) deteriorates the match from the surface to $3000 \mathrm{~m}$ altitude. As discussed before, EDGAR, GFEDv2 and D2003 emissions typically result in a much cleaner PBL and lower troposphere than shown by the observations.

\subsection{Model comparisons with MOPITT CO data}

The model performance on larger scales and including midto upper tropospheric levels is evaluated in this section, using data retrieved by the "Measurements of Pollution in the Troposphere" (MOPITT) instrument onboard the Earth Observing System Terra satellite. MOPITT retrievals of tropospheric CO mixing ratio (ppb) are reported for 7 pressure 


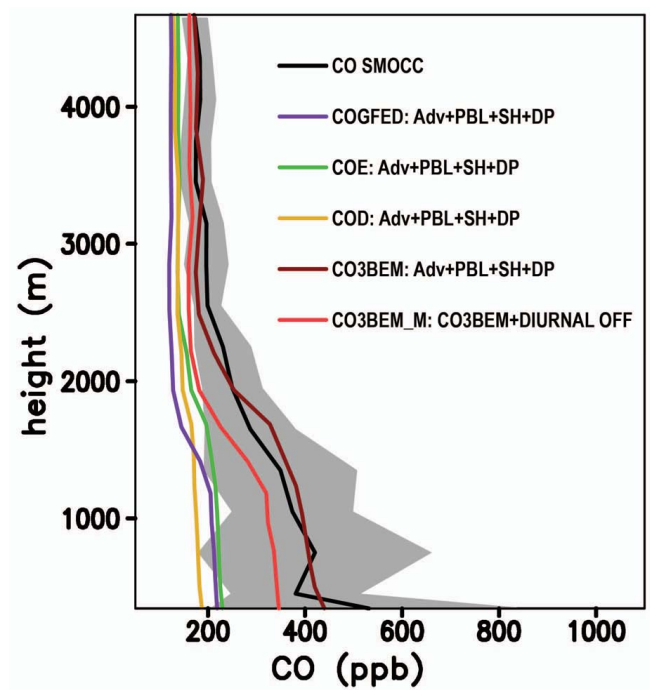

Fig. 8. Comparison between the mean $\mathrm{CO}$ mixing ratio (ppb) observed during sixteen flights of the SMOCC/RaCCI field campaign (black solid line represents the mean while the grey zone shows the standard deviation range) and the mean of model results using the EDGAR inventory (green), D2003 (orange), 3BEM (CO3BEM, dark red), 3BEM monthly mean (CO3BEM_M, red) and GFEDv2 (purple).

levels, from the surface to $150 \mathrm{hPa}$ (Deeter et al., 2003). Because MOPITT data have large horizontal areas without valid data due to swath width and cloud cover, the MOPITT data and the corresponding model results were monthly averaged, after applying the averaging kernel and a priori profile and using only retrievals with $<50 \%$ a priori contribution. Figures 9 and 10 show the comparisons for the months of August and October, respectively, and at levels 700, 500, and $250 \mathrm{hPa}$. September showed similar results and the associated figure is not included in this paper. Additionally, MOPITT retrievals are less reliable at low levels due to the typically stronger influence of the assumed a priori for retrieved surface level CO concentration than for higher levels (Deeter et al., 2003). The comparison is quantified by the relative model error (ME) defined as

$\mathrm{ME}=100 \cdot \frac{\mathrm{CO}_{\text {mopitt }}-\mathrm{CO}_{\text {model }}}{\mathrm{CO}_{\text {mopitt }}}$

where $\mathrm{CO}_{\text {model }}$ is the monthly mean of the model $\mathrm{CO}$ mixing ratio after applying the averaging kernel and a priori fraction $<50 \%$. According to the above definition, positive values mean that model results are underestimated in reference to the MOPITT retrieved data and vice-versa. In the Figs. 9 and 10 , the model results for $\mathrm{CO}$ from $3 \mathrm{BEM}$ are in the first line; the second line refers to 3BEM monthly mean and, subsequently, GFEDv2, D2003 and EDGAR.

Comparing results for August (Fig. 9), 3BEM presents smaller errors relative to the MOPITT retrievals than EDGAR, D2003 and GFEDv2 at all vertical levels. South

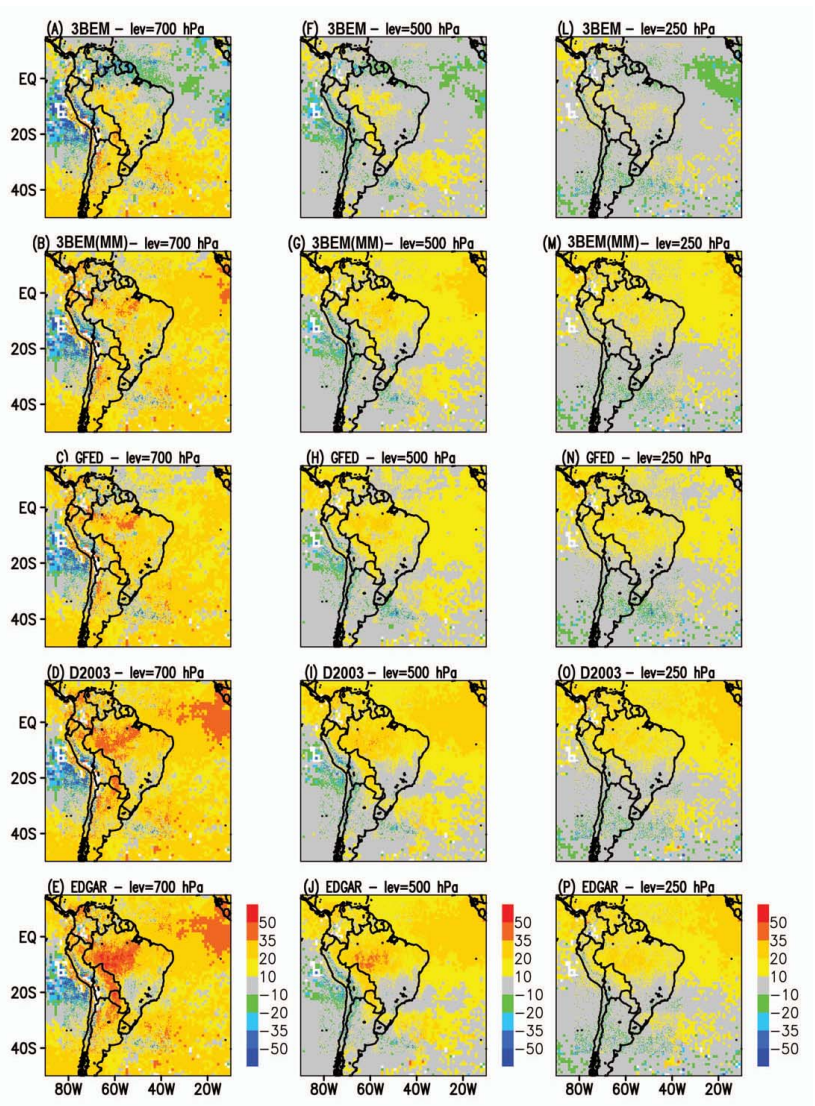

Fig. 9. CO model relative error $(\%)$ associated with the five emission estimates in reference to the MOPITT CO retrieval for August 2002 at 3 vertical levels $(700,500$ and $250 \mathrm{hPa})$. Positive values mean that model results are underestimated in reference to the MOPITT retrieved data and vice-versa.

of $30^{\circ} \mathrm{S}$, ME presents higher absolute values mainly in the lower levels. However, in this region it is very difficult to assess the model performance because the concentration of tracers is mostly determined by the lateral boundary condition at the model eastern border, and usually not affected by the biomass burning emissions in SA. Also, the regions where 3BEM has larger model errors are smaller in terms of area coverage than for EDGAR, GFEDv2 and D2003; this characteristic is due to the coarse-scale spatial emission of these inventories. Over SA during August, the model error for the 250 and $500 \mathrm{hPa}$ levels was below typically $10 \%$, with few areas of $20 \%$ over the Amazon for 3BEM, while for the other three inventories it ranged from $20 \%$ to $35 \%$ with a few areas reaching $50 \%$. For the $700 \mathrm{hPa}$ level, the 3BEM also presents better skill over SA compared to EDGAR, GFEDv2 and D2003, with the 3BEM model error typically below $20 \%$, against $35-50 \%$ for the other models.

Noticeable is the huge degradation of 3BEM results when the monthly-mean emission is used (see 2nd line of Fig. 9, $3 \mathrm{BEM}(\mathrm{MM})$ ), which indicates the importance of including 

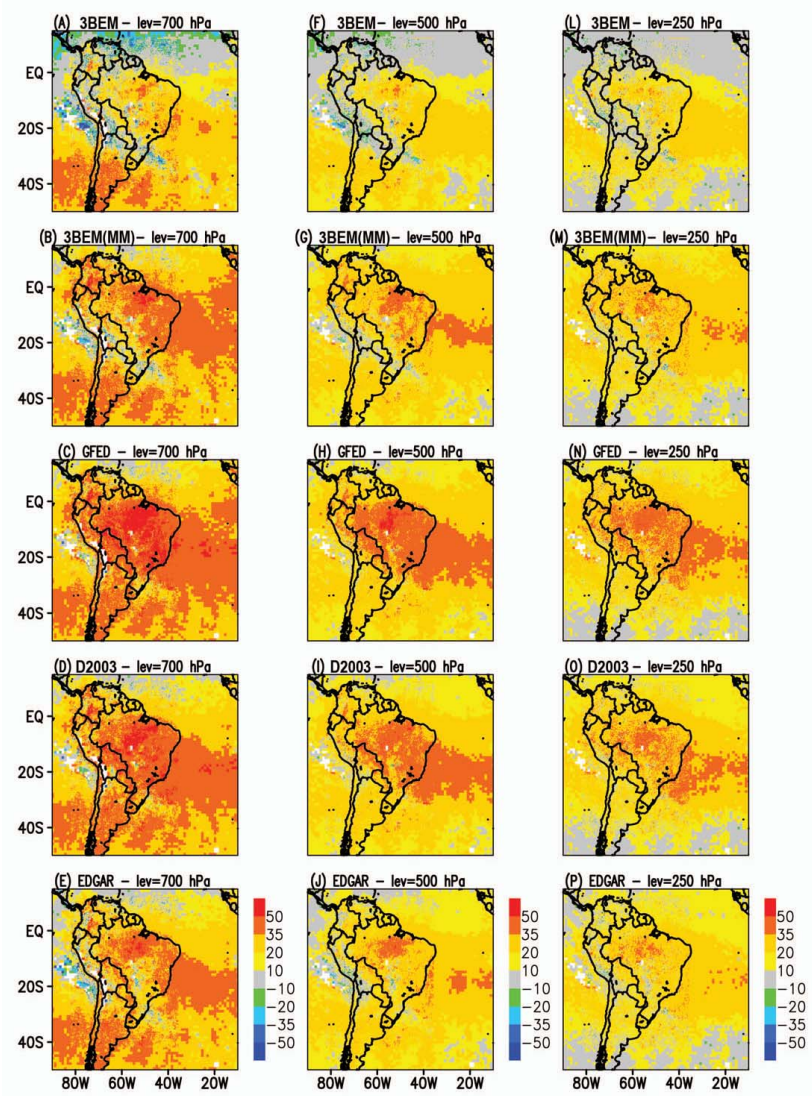

Fig. 10. CO model relative error (\%) associated with the five emission estimates in reference to the MOPITT CO retrieval for October 2002 at 3 vertical levels $(700,500$ and $250 \mathrm{hPa})$. Positive values mean that model results are underestimated in reference to the MOPITT retrieved data and vice-versa.

fire emissions at the right time resolution. Otherwise, the combination of a monthly mean emission and the 3-D transports increase the model errors not only on its absolute value but also results in inaccurate spatial distributions.

For October (Fig. 10), although 3BEM model errors were greater than for August, 3BEM still showed better skill than EDGAR, GFEDv2 and D2003, for similar reasons.

The underestimated model CO showed in this section may be partially attributed to the approach using a fixed CO lifetime of 30 days. Further studies are necessary to corroborate or refuse this attribution.

\section{Discussion and conclusions}

A biomass burning emission technique developed for South America, named 3BEM, has been described and evaluated via performance analysis of the atmospheric transport model CATT-BRAMS against observations. The features of 3BEM include a fine spatial resolution, adjustable to the resolution of the atmospheric transport model, and a temporal resolu- tion that includes realistic daily and even diurnal cycling. The results using 3BEM were compared to those obtained using three other biomass burning emissions inventories: EDGAR, D2003 and GFEDv2. The EDGAR and D2003 inventories are fundamentally climatological with $2.5^{\circ}$ and $1.0^{\circ}$ spatial resolution, respectively, and monthly temporal resolution, while GFEDv2 has $1.0^{\circ}$ spatial resolution but 8day time variation. We also discuss the effect of using the daily time resolution of fire emissions in 3BEM by comparing results obtained using monthly averages of the $3 \mathrm{BEM}$ emission fields.

In general, the performance of the CATT-BRAMS model fed with 3BEM against observations is superior to results obtained with the other three inventories. This was true for all scales of evaluation: local, regional and large-scale. Although the 3BEM inventory is based on a very simple approach and relies on input parameters with well-known inaccuracies, it is actually capable of providing valid estimates of the biomass burning emission fields, as long as appropriate input parameters are chosen.

As demonstrated by Fig. 5, the inclusion of daily variability seems to be crucial to capturing the near-surface $\mathrm{CO}$ time variability observed over Rondonia during the field campaign. Using monthly averages of 3BEM emissions caused the correlation between simulation and observations to be reduced from 0.69 to 0.33 . For the lower troposphere, using monthly averages degraded the comparison of the simulated CO concentrations from the surface up to 3000 meters altitude. On the large scale, comparison with MOPITT $\mathrm{CO}$ retrievals indicates similar findings: the combination of monthly-mean emissions and 3-D transport increased the model errors not only regarding the absolute values, but as also distorted the spatial distribution, which became much more washed out.

The promising agreement between model results and local observations as well as remote-sensing-derived data of $\mathrm{CO}$ at several scales (local to large-scale) shown in this paper, as well as by Freitas et al. (2006, 2009), indicate that 3BEM is a valid approach to modeling biomass burning emissions for South America. Extending this kind of approach to other regions, however, requires the availability of detailed datasets as described above, as well as fire count information in terms of location, timing, diurnal cycle and estimated fire size and/or burnt area.

Acknowledgements. We acknowledge partial support of this work by NASA Headquarters (NRA-03-OES-02 and NRA-02-OES-06), CNPq (305059/2005-0 and 309922/2007-0). This work was carried out within the framework of the project "Monitoramento de emissões de queimadas e avaliação das observações de qualidade do ar em Três Lagoas - MS" in collaboration with CENPES/Petrobras; the LBA Smoke, Aerosols, Clouds, Rainfall, and Climate (SMOCC) project (funded by the Environmental and Climate Program of the European Commission under contract $\mathrm{N}^{\circ}$ EVK2-CT-2001-00110-SMOCC and by the Max Planck Society), and Radiation, Cloud, and Climate Interactions in the Amazon 
during the DRY-TO-WET Transition Season (RACCI) project (funded by FAPESP and Instituto do Milenio/LBA/CNPq/MCT).

Edited by: M. G. Lawrence

\section{References}

Andreae, M.: Biomass burning: its history, use and distribution and its impact on environmental quality and global climate. In: J. S. Levine (ed.), Global Biomass Burning: Atmospheric, Climatic and Biospheric Implications, MIT Press, Cambridge, Mass, 321, 1991.

Andreae, M. and Merlet, P.: Emission of trace gases and aerosols from biomass burning, Global Biogeochem. Cy., 15, 4, 955-966, 2001.

Andreae, M., Rosenfeld, D., Artaxo, P., Costa, A., Frank, G., Longo, K. M., and Silva Dias, M. A. F.: Smoking rain clouds over the Amazon, Science, 303, 1342-1345, 2004.

Belward, A.: The IGBP-DIS global $1 \mathrm{~km}$ land cover data set (DISCover)-proposal and implementation plans, IGBP-DIS Working Paper No. 13, Toulouse, France, 1996.

Deeter, M. N., Emmons, L. K., Francis, G. L., Edwards, D. P., Gille, J. C., Warner, J. X., Khattatov, B., Ziskin, D., Lamarque, J.-F., Ho, S.-P., Yudin, V., Attié, J.-L., Packman, D., Chen, J., Mao, D., and Drummond, J. R.: Operational carbon monoxide retrieval algorithm and selected results for the MOPITT instrument, J. Geophys. Res., 108(D14), 4399, doi:10.1029/2002JD003186, 2003.

Duncan, B., Martin, R., Staudt, A., Yevich, R., and Logan, J.: Interannual and seasonal variability of biomass burning emissions constrained by satellite observations, J. Geophys. Res., 108(D2), 4100, doi:10.1029/2002JD002378, 2003.

Freeborn, P. H., Wooster, M. J., Hao, W. M., Ryan, C. A., Nordgren, B. L., Baker S. P., and Ichoku, C.: Relationships between energy release, fuel mass loss, and trace gas and aerosol emissions during laboratory biomass fires, J. Geophys. Res., 113, D01301, doi:10.1029/2007JD008679, 2008.

Freitas, S. R., Longo, K. M., Silva Dias, M., Silva Dias, P., Chatfield, R., Prins, E., Artaxo, P., Grell, G., and Recuero, F.: Monitoring the transport of biomass burning emissions in South America, Environ. Fluid Mech., 5(1-2), 135-167, doi:10.1007/s10652-005-0243-7, 2005.

Freitas, S. R., Longo, K. M., and Andreae, M. O.: Impact of including the plume rise of vegetation fires in numerical simulations of associated atmospheric pollutants, Geophys. Res. Lett., 33, L17808, doi:10.1029/2006GL026608, 2006.

Freitas, S. R., Longo, K. M., Silva Dias, M. A. F., Chatfield, R., Silva Dias, P., Artaxo, P., Andreae, M. O., Grell, G., Rodrigues, L. F., Fazenda, A., and Panetta, J.: The Coupled Aerosol and Tracer Transport model to the Brazilian developments on the Regional Atmospheric Modeling System (CATT-BRAMS) - Part 1: Model description and evaluation, Atmos. Chem. Phys., 9, 28432861, doi:10.5194/acp-9-2843-2009, 2009.

Generoso, S., Bréon, F.-M., Balkanski, Y., Boucher, O., and Schulz, M.: Improving the seasonal cycle and interannual variations of biomass burning aerosol sources, Atmos. Chem. Phys., 3, 12111222, doi:10.5194/acp-3-1211-2003, 2003.

Giglio, L., Descloitres, J., Justice, C. O., and Kaufman, Y. J.: An enhanced contextual fire detection algorithm for MODIS, Remote Sens. Environ., 87, 273-282, 2003.
Giglio, L., van der Werf, G. R., Randerson, J. T., Collatz, G. J., and Kasibhatla, P.: Global estimation of burned area using MODIS active fire observations, Atmos. Chem. Phys., 6, 957974, doi:10.5194/acp-6-957-2006, 2006.

Hao, W. M. and Liu, M.-H.: Spatial and temporal distribution of tropical biomass burning, Global Biogeochem. Cy., 8(4), 495504, 1994.

Hoelzemann, J. J., Schultz, M. G., Brasseur, G. P., Granier, C., and Simon, M.: Global Wildland Fire Emission Model (GWEM): Evaluating the use of global area burnt satellite data, J. Geophys. Res., 109, D14S04, doi:10.1029/2003JD003666, 2004.

Hoelzemann, J. J.: Global Wildland Fires Impact on Atmospheric Chemistry, Saarbruecken, Alemanha: VDM-Verlag Dr. Müller, 200 pp., 2007.

Houghton, R. A., Lawrence, K. T., Hackler, J. L., and Brown, S.: The spatial distribution of forest biomass in the Brazilian Amazon: a comparison of estimates, Glob. Change Biol., 7(7), 731746, 2001.

Ichoku, C. and Kaufman, Y. J.: A method to derive smoke emission rates from MODIS fire radiative energy measurements, IEEE T. Geosci. Remote, 43(11), 2636-2649, 2005.

Kaufman, Y.: Remote sensing of direct and indirect aerosol forcing, in: Aerosol Forcing of Climate, edited by: Charlson, R. J. and Heintzenberg, J., John Wiley \& Sons Ltd, Chichester, 297-332, 1995.

Kaufman, Y. J., Ichoku, C., Giglio, L., Korontzi, S., Chu, D. A., Hao, W. M., Li, R.-R., and Justice, C. O.: Fire and smoke observed from the Earth Observing System MODIS instrumentproducts, validation, and operational use, Int. J. Remote Sens., 24(8), 1765-1781, 2003.

Koren, I., Remer L. A., and Longo K.: Reversal of trend of biomass burning in the Amazon, Geophys. Res. Lett., 34, L20404, doi:10.1029/2007GL031530, 2007.

Koren, I., Remer L. A., Longo, K., Foster, B., and Rebecca, L.: Reply to comment by W. Schroeder et al. on "Reversal of trend of biomass burning in the Amazon", Geophys. Res. Lett., 36, L03807, doi:10.1029/2008GL036063, 2009.

Lobert, J. M., Keene, W. C., Logan, J. A., and Yevich, R.: Global chlorine emissions from biomass burning: Reactive Chlorine Emissions Inventory, J. Geophys. Res., 104(D7), 8373-8389, 1999.

Mauzerall, D., Logan, J., Jacob, D., Anderson, B., Blake, D., Bradshaw, J., Heikes, B., Sachse, G., Singh, H., and Talbot, B.: Photochemistry in biomass burning plumes and implications for tropospheric ozone over the tropical South Atlantic, J. Geophys. Res., 103(D7), 8401-8423, 1998.

Olson, J. S., Watts, J. A., and Allison, L. J.: Major World Ecosystem Complexes Ranked by Carbon in Live Vegetation: A Database (Revised November 2000). NDP-017, available online at: http: //cdiac.esd.ornl.gov/ndps/ndp017.html from Carbon Dioxide Information Analysis Center, Oak Ridge National Laboratory, Oak Ridge, Tennessee, USA, 2000.

Olivier, J., Bouwman, A., van der Maas, C., Berdowski, J., Veldt, C., Bloos, J., Visschedijk, A., Zandveld, P., and Haverlag, J.: Description of EDGAR Version 2.0: A Set of Global Emission Inventories of Greenhouse Gases and Ozone-Depleting Substances for All Anthropogenic and Most Natural Sources on a per Country Basis and on a 1x1 Degree Grid, RIVM Report 771060 002/TNO-MEP Report R96/119, National Institute of 
Public Health and the Environment, Bilthoven, The Netherlands, 1996.

Olivier, J., Bouwman, A., Berdowski, J., Veldt, C., Bloos, J., Visschedijk, A., van der Maas, C., and Zandveld, P.: Sectoral emission inventories of greenhouse gases for 1990 on a per country basis as well as on 1x1 degree, Environ. Sci. Policy, 2, 241-264, 1999.

Pereira, G., Freitas, S. R., Moraes, E. C., Ferreira, N. J., Shimabukuro, Y., Rao, V., and Longo, K. M.: Estimating trace gas and aerosol emissions over South America: Relationship between fire radiative energy released and aerosol optical depth observations, Atmos. Environ., 43, 6388-6397, 2009.

Prins, E., Feltz, J., Menzel, W., and Ward, D.: An overview of GOES-8 diurnal fire and smoke results for SCAR-B and 1995 fire season in South America, J. Geophys. Res., 103(D24), 3182131835, 1998.

Riggan, P., Tissell, R., Lockwood, R., Brass, J., Pereira, J., Miranda, H., Miranda, A., Campos, T., and Higgins, R.: Remote measurement of energy and carbon flux from wildfires in Brazil, Ecol. Appl., 14(3), 855-872, 2004.

Schroeder, W., Giglio L., and Aravéquia J. A..: Comment on "Reversal of trend of biomass burning in the Amazon" by Ilan Koren, Lorraine A. Remer, and Karla Longo, Geophys. Res. Lett., 36, L03806, doi:10.1029/2008GL035659, 2009.

Seinfeld, J. and Pandis, S.: Atmospheric Chemistry and Physics, John Wiley \& Sons Inc., New York, 1998.

Sestini, M., Reimer, E., Valeriano, D., Alvalá, R., Mello, E., Chan, C., and Nobre, C.: Mapa de cobertura da terra da Amazônia legal para uso em modelos meteorológicos, Anais XI Simpósio Brasileiro de Sensoriamento Remoto, 2901-2906, 2003.
Setzer, A. and Pereira, M.: Amazonia biomass burnings in 1987 and an estimate of their tropospheric emissions, Ambio, 20, 19-22, 1991.

Schultz, M. G.: On the use of ATSR fire count data to estimate the seasonal and interannual variability of vegetation fire emissions, Atmos. Chem. Phys., 2, 387-395, doi:10.5194/acp-2-387-2002, 2002.

Trebs, I., Meixner, F. X., Slanina, J., Otjes, R., Jongejan, P., and Andreae, M. O.: Real-time measurements of ammonia, acidic trace gases and water-soluble inorganic aerosol species at a rural site in the Amazon Basin, Atmos. Chem. Phys., 4, 967-987, doi:10.5194/acp-4-967-2004, 2004.

van der Werf, G. R., Randerson, J. T., Giglio, L., Collatz, G. J., Kasibhatla, P. S., and Arellano Jr., A. F.: Interannual variability in global biomass burning emissions from 1997 to 2004, Atmos. Chem. Phys., 6, 3423-3441, doi:10.5194/acp-6-3423-2006, 2006.

Yevich, R. and Logan, J.: An assessment of biofuel use and burning of agricultural waste in the developing world, Global Biogeochem. Cy., 17(4), 1095, doi:10.1029/2002GB001952, 2003.

Ward, E., Susott, R., Kaufman, J., Babbit, R., Cummings, D., Dias, B., Holben, B., Kaufman, Y., Rasmussen, R., and Setzer, A.: Smoke and fire characteristics for cerrado and deforestation burns in Brazil: BASE-B Experiment, J. Geophys. Res., 97(D13), 14601-14619, 1992.

Wooster, M. J., Roberts, G., and Perry, G. L. W.: Retrieval of biomass combustion rates and totals from fire radiative power observations: FRP derivation and calibration relationships between biomass consumption and fire radiative energy release, J. Geophys. Res., 110, D24311, doi:10.1029/2005JD006318, 2005. 